\title{
REVIEW
}

\section{Clinical review: Optimal dose of continuous renal replacement therapy in acute kidney injury}

John R Prowle, Antoine Schneider and Rinaldo Bellomo*

\begin{abstract}
Continuous renal replacement therapy (CRRT) is the preferred treatment for acute kidney injury in intensive care units (ICUs) throughout much of the world. Despite the widespread use of CRRT, controversy and centerspecific practice variation in the clinical application of CRRT continue. In particular, whereas two single-center studies have suggested survival benefit from delivery of higher-intensity CRRT to patients with acute kidney injury in the ICU, other studies have been inconsistent in their results. Now, however, two large multi-center randomized controlled trials - the Veterans Affairs/ National Institutes of Health Acute Renal Failure Trial Network (ATN) study and the Randomized Evaluation of Normal versus Augmented Level (RENAL) Replacement Therapy Study - have provided level 1 evidence that effluent flow rates above $25 \mathrm{~mL} / \mathrm{kg}$ per hour do not improve outcomes in patients in the ICU. In this review, we discuss the concept of dose of CRRT, its relationship with clinical outcomes, and what target optimal dose of CRRT should be pursued in light of the high-quality evidence now available.
\end{abstract}

\section{Introduction}

Extracorporeal renal replacement therapy (RRT) has been used for the supportive treatment of acute kidney injury (AKI) for over 60 years. Whereas treatment methodologies have become increasingly sophisticated, the basic principles guiding the use of RRT have changed little. They aim at averting the immediately life-threatening consequences of severe renal dysfunction (acidosis, electrolyte imbalances, uremia, and fluid overload), preserving life, and allowing time for organ recovery to occur. Following these principles, one could argue that, as long as a minimum level of RRT is provided, the

*Correspondence: rinaldo.bellomo@austin.org.au

Department of Intensive Care, Austin Health, 145 Studley Road, Heidelberg, Victoria 3084, Australia quality, quantity, and timing of RRT should not greatly affect outcome. However, considerable evidence that the development of AKI is independently associated with mortality now exists [1], suggesting that optimization of RRT could benefit survival. Until now, however, little evidence or consensus regarding the optimum delivery of RRT has existed, resulting in wide variations in clinical practice [2]. Furthermore, irrespective of intensity, the superiority of continuous renal replacement therapy (CRRT) over intermittent hemodialysis (IHD) for RRT in the intensive care unit (ICU) remains controversial, although there is increasing international consensus that initial therapy with CRRT is preferable in hemodynamically unstable patients [3-6]. Given that most patients critically ill with AKI do have hemodynamic instability, CRRT has become, worldwide, the dominant form of RRT for AKI in the ICU [2]. Furthermore, since a large majority of RRT treatments for AKI are now given in the ICU [7], CRRT is likely to be the most common modality for the initial treatment of AKI by RRT in the developed world.

As a continuous therapy, CRRT has the benefit of better mimicking normal renal function, while quantity of therapy delivered is more easily assessed and compared with endogenous renal function. Consequently, there has been continued interest in establishing the appropriate dose or intensity of this therapy. Two major multi-center randomized controlled trials (MC-RCTs) examining this question have now been performed: the Veterans Affairs/ National Institutes of Health Acute Renal Failure Trial Network (ATN) study [4] and the Randomized Evaluation of Normal versus Augmented Level (RENAL) Replacement Therapy Study [8]. Together, these trials provide, for the first time, high-quality evidence to guide the prescription of CRRT in the ICU. This review examines the results from these and earlier studies to summarize our current understanding of the most appropriate dose of CRRT to deliver during AKI in critical illness.

\section{Assessing dose of continuous renal replacement therapy}

To compare differing intensities of RRT, some measure of quantity of blood cleansing is needed. Quantity or dose of 
RRT delivered is traditionally assessed by measuring clearance of urea (that is, the rate of plasma cleansing required to account for the rate of urea removal if the treatment separated all urea from the plasma processed). Such measurements are comparable to endogenous renal function assessed as glomerular filtration rate (GFR). Urea is chosen as an easily measured prototype for lowmolecular-weight products of metabolism. While tubular reabsorption prevents urea clearance from being an accurate measure of kidney GFR, such concerns do not apply to extracorporeal blood purification. Measuring total urea in the dialysis or ultrafiltration effluent and continuous plasma urea concentration could allow calculation of clearance. However, this is cumbersome and approximations of dose are instead estimated from machine settings. This process is very easy for continuous therapies. For a small uncharged molecule such as urea, clearance during continuous hemofiltration (HF) is essentially equal to the ultrafiltration rate because the filter membrane negligibly impedes the passage of urea. Similarly, during continuous hemodialysis (HD), when the dialysis flow rate is much slower than the blood flow rate, urea concentration in the dialysate will equilibrate with that in the plasma and clearance can be approximated by the dialysate flow rate. Thus, provided that no pre-dilution is applied, in any HF, HD, or hemodiafiltration continuous therapy, the total clearance is approximately the total flow of fluid out of the dialyzer or filter (that is, the effluent flow rate).

The above approximations have been shown to correlate well with a more formal set of measurements of urea clearance [9]. Thus, the dose of CRRT is reported as effluent flow in milliliter per hour or milliliter per kilogram of body weight per hour. Infusion of HF replacement solution as pre-dilution will reduce effective effluent dose by the degree to which the plasma is diluted. Since this dilution effect is dependent on circuit blood flow, replacement fluid rate, and hematocrit, these factors have to be measured to correctly assess dose when predilution is applied [9]. Most importantly, time spent off CRRT (circuit clotting, radiological investigations, and/ or surgical procedures) can be substantial and can impact azotemic control [10]. The impact of these factors must be accounted for when prescribing therapy as it is the delivered and not the prescribed dose that will affect outcome. Finally, unlike urea, metabolites of higher molecular weight will interact significantly with the dialyzer membrane. Similarly, other substances that significantly bind to plasma proteins may be relatively retained in the plasma. In these cases, changes in effluent flow rate may correlate poorly with changes in solute clearance. Thus, it should be remembered that effluent measures of dose, while reproducible and convenient, do not measure all aspects of blood cleansing in CRRT.

\section{Clinical variation in continuous renal replacement therapy dose}

Prescribed and delivered intensities of CRRT vary widely. Two multi-center observational studies have documented CRRT dose in the ICU; in both studies, interquartile ranges for dose were large (15.3 to $27.7 \mathrm{~mL} / \mathrm{kg}$ per hour in the BEST Kidney [Beginning and Ending Supportive Therapy for the Kidney] study [11] and 22.1 to $33.9 \mathrm{~mL} /$ $\mathrm{kg}$ per hour in the DO-RE-MI [Dose Response Multicentre International collaborative initiative] study [12]). As units participating in these studies were recruited by expression of interest, one can assume far wider variation and lower delivered doses in units without an interest in research and the provision of CRRT. Much of this variation in dose may be accounted for by the use of standard doses of CRRT unadjusted for weight. For example, in the DO-RE-MI study, patients receiving the lowest CRRT doses were 33\% heavier than those receiving the higher doses [13]. This greatly confounds the interpretation of observational data on CRRT dose since weight is likely to have a complex causal relationship with outcome. Furthermore, even when used, weight estimation in the ICU can be highly errorprone and it is far from clear whether estimates of ideal body weight, pre-morbid weight, 'dry' weight, or actual body weight should be used [13].

\section{Dose-response relationship in continuous renal replacement therapy}

Prior to the ATN and RENAL trials, four single-center studies had prospectively examined the relationship between CRRT dose and survival in critical illness (Table 1). All of these trials were, however, relatively small and varied in geographical location, patient case mix, and mode of CRRT. In the first of these, Ronco and colleagues [14] randomly assigned 425 critically ill patients with AKI treated using continuous veno-venous hemofiltration (CVVHF) at a single center to ultrafiltration rates of 20 , 35 , or $45 \mathrm{~mL} / \mathrm{kg}$ per hour. Survival 15 days after discontinuation of CRRT was significantly better in the highestand intermediate-dose arms in comparison with the lowest-dose arm (58\% and $57 \%$ versus $41 \%$, respectively; $P<0.001)$. Three smaller randomized control trials subsequently examined RRT dose-response relationships in the ICU. Saudan and colleagues [15] randomly assigned 206 patients with AKI in a single-center trial comparing CVVHF (mean ultrafiltration rate of $25 \pm 5 \mathrm{~mL} / \mathrm{kg}$ per hour) with continuous veno-venous hemodiafiltration (CVVHDF) with the addition of a mean dialysate flow rate of $15 \pm 5 \mathrm{~mL} / \mathrm{kg}$ per hour to a similar mean ultrafiltration rate ( $24 \pm 6 \mathrm{~mL} / \mathrm{kg}$ per hour): survival rates after 90 days were $34 \%$ in the CVVHF group and 59\% in the CVVHDF group $(P=0.0005)$, analyzed on an intentionto-treat basis. While higher-intensity therapy involved a 
Table 1. Randomized controlled trials comparing dose of continuous renal replacement therapy in the intensive care unit

\begin{tabular}{|c|c|c|c|c|c|}
\hline Study & Type & Number & Comparison & $\begin{array}{l}\text { Survival } \\
\text { (measured at) }\end{array}$ & Comment \\
\hline \multirow[t]{3}{*}{ RENAL [8] 2009} & MC-RCT & 1,508 & $40 \mathrm{~mL} / \mathrm{kg}$ per hour versus & $55 \%$ (day 90 ) & \\
\hline & & & $25 \mathrm{~mL} / \mathrm{kg}$ per hour & $55 \%$ NS & \\
\hline & & & Post-dilution CVHDF & & \\
\hline \multirow[t]{2}{*}{ ATN [4] 2008} & MC-RCT & 1,124 & $\begin{array}{l}\text { Pre-dilution CVVHDF } 35 \mathrm{~mL} / \mathrm{kg} \text { per } \\
\text { hour or } 6 / \text { week SLEDD or 6/week } \\
\text { IHD versus }\end{array}$ & $46 \%$ (day 60 ) & $\begin{array}{l}\text { Choice of CRRT/SLEDD versus IHD } \\
\text { based on daily cardiovascular SOFA } \\
\text { score. }\end{array}$ \\
\hline & & & $\begin{array}{l}\text { Pre-dilution CVVHDF } 20 \text { mL/kg per } \\
\text { hour or 3/week SLEDD or 3/week IHD }\end{array}$ & $48 \%$ NS & \\
\hline \multirow[t]{3}{*}{ Tolwani, et al. [17] 2008} & SS-RCT & 200 & 17 mL/kg per hour & $49 \%$ (ICU or 30 days) & \\
\hline & & & $29 \mathrm{~mL} / \mathrm{kg}$ per hour & $56 \%$ NS & \\
\hline & & & Pre-dilution CVHDF (delivered doses) & & \\
\hline \multirow[t]{2}{*}{ Saudan, et al. [15] 2006} & SS-RCT & 206 & CVHF: 1-2.5 L/hour versus & $34 \%$ (day 90 ) & \\
\hline & & & $\begin{array}{l}\text { CVHDF: } 1-2.5 \text { L/hour HF }+ \\
1-1.5 \text { L/hour HD }\end{array}$ & $59 \% P=0.0005$ & \\
\hline \multirow[t]{4}{*}{ Bouman, et al. [18] 2002} & 2C-RCT & 106 & 72-96 L/day early versus & $74 \%$ (day 28) & $\begin{array}{l}\text { Combined trial of dose and timing } \\
\text { early versus late. }\end{array}$ \\
\hline & & & 24-36 L/day early versus & $69 \%$ NS & \\
\hline & & & 24-36 L/day late & $75 \%$ NS & \\
\hline & & & CVHF & & \\
\hline \multirow[t]{5}{*}{ Ronco, et al. [14] 2000} & SS-RCT & 425 & $20 \mathrm{~mL} / \mathrm{kg}$ per hour versus & $59 \%$ (day 15) & $\begin{array}{l}\text { Unorthodox mortality outcome (day } \\
15 \text { after CRRT). }\end{array}$ \\
\hline & & & $35 \mathrm{~mL} / \mathrm{kg}$ per hour versus & $43 \%$ & \\
\hline & & & $45 \mathrm{~mL} / \mathrm{kg}$ per hour & $42 \%$ & \\
\hline & & & Post-dilution CVHF & $\begin{array}{l}20 \text { versus } 35 \text { or } 45 \\
P<0.002\end{array}$ & \\
\hline & & & & 35 versus 45 NS & \\
\hline
\end{tabular}

2C-RCT, two-center randomized controlled trial; ATN, Veterans Affairs/National Institutes of Health Acute Renal Failure Trial Network; CRRT, continuous renal replacement therapy; CVVHDF, continuous veno-venous hemodiafiltration; CVVHF, continuous veno-venous hemofiltration; HD, hemodialysis; HF, hemofiltration; ICU, intensive care unit; IHD, intermittent hemodialysis; MC-RCT, multi-center randomized controlled trial; NS, not significant; RENAL, Randomized Evaluation of Normal versus Augmented Level; SOFA, Sequential Organ Failure Assessment; SLEDD, slow extended-duration daily dialysis; SS-RCT, single-center randomized controlled trial.

different modality, evidence suggests that solute clearances in continuous high-flux dialysis and CVVHF are quite similar [16], so this study is best regarded as investigating the effect of a dose increment.

On the other hand, two studies $[17,18]$ that included 200 and 106 patients, respectively, failed to demonstrate any beneficial effects of increased CRRT intensity on patient survival or renal recovery. Similarly, in the prospective observational DO-RE-MI study [12], which included 338 patients undergoing CRRT for AKI in the ICU, higher-dose CRRT (defined as greater than $35 \mathrm{~mL} / \mathrm{kg}$ per hour) was not associated with increased survival even after statistical adjustment for baseline characteristics (adjusted odds ratio for death 1.21, 95\% confidence interval 0.66 to $2.21 ; P=0.537$ ). Disparity in these results, concerns over the inherent biases of single-center studies [19], and consequent uncertainty about the optimum dosing of CRRT in the ICU led to the initiation of the ATN and RENAL studies.
The ATN and RENAL studies were large, multi-center randomized controlled trials investigating the effects of RRT dose on survival and were conducted in ICUs throughout the US and in Australia and New Zealand, respectively (Table 2). The ATN study [4] randomly assigned critically ill adults with AKI that required RRT to high-intensity or low-intensity RRT. High-intensity therapy consisted of pre-dilution CVVHDF to provide a total effluent flow rate of $35 \mathrm{~mL} / \mathrm{kg}$ per hour or six sessions of IHD per week [4]. Low-intensity therapy consisted of CVVHDF to provide a total effluent flow rate of $20 \mathrm{~mL} / \mathrm{kg}$ per hour or thrice-weekly IHD. A very small number of patients received slow extended-duration dialysis six or three times weekly in the highintensity and low-intensity groups, respectively, in centers where CRRT was not available [4]. Within treatment groups, patients were allocated to CRRT or IHD when their cardiovascular Sequential Organ Failure Assessment (SOFA) score was 3 or 4 and received IHD if 
Table 2. Comparison of patient populations in VA/NIH ATN and RENAL studies

\begin{tabular}{|c|c|c|}
\hline & VA/NIH ATN study & RENAL study \\
\hline Number & 1,124 & 1,508 \\
\hline Age, years & 59.7 & 64.5 \\
\hline Percentage of males & $70.6 \%$ & $64.6 \%$ \\
\hline \multicolumn{3}{|l|}{ CKD classification ${ }^{a}$} \\
\hline $0-2$ & $61.0 \%$ & $68.6 \%$ \\
\hline $3 a$ & $21.1 \%$ & $9.7 \%$ \\
\hline $3 b$ & $11.0 \%$ & $10.4 \%$ \\
\hline 4 & Excluded & $11.3 \%$ \\
\hline 5 & Excluded & Excluded \\
\hline Sepsis & $63.0 \%$ & $47.9 \%$ \\
\hline Mechanical ventilation & $80.6 \%$ & $73.9 \%$ \\
\hline IIIness severity score & APACHE II: 26.4 & APACHE III: 102.4 \\
\hline $\begin{array}{l}\text { Total SOFA score (respiratory, cardiovascular, } \\
\text { liver, coagulation) }\end{array}$ & 7.55 & 7.40 \\
\hline Modalities of RRT & CWVHDF, SLEDD, or IHD & CVHHDF \\
\hline RRT prior to randomization & $\begin{array}{l}64.3 \% \text { (only patients who had undergone fewer } \\
\text { than two sessions of IHD or SLEDD or less than } \\
24 \text { hours CRRT were included) }\end{array}$ & $0 \%$ (patients with prior RRT excluded) \\
\hline Commenced on CRRT & $69.7 \%$ & $100 \%$ \\
\hline CRRT mode & Pre-dilution CVVHDF & Post-dilution CVVHDF \\
\hline CRRT high-dose effluent target & $35 \mathrm{~mL} / \mathrm{kg}$ per hour & $40 \mathrm{~mL} / \mathrm{kg}$ per hour \\
\hline CRRT low-dose effluent target & $20 \mathrm{~mL} / \mathrm{kg}$ per hour & $25 \mathrm{~mL} / \mathrm{kg}$ per hour \\
\hline Time from ICU admission to first study RRT & 6.7 days & 2.1 days \\
\hline Urea at study enrolment & $23.8 \mathrm{mmol} / \mathrm{L}$ & $24.2 \mathrm{mmol} / \mathrm{L}$ \\
\hline Achieved dose of CRRT (high dose) & $27.1 \mathrm{~mL} / \mathrm{kg}$ per hour ${ }^{\mathrm{b}}$ & $33.4 \mathrm{~mL} / \mathrm{kg}$ per hour \\
\hline Achieved dose of CRRT (low dose) & $17.5 \mathrm{~mL} / \mathrm{kg}$ per hour ${ }^{\mathrm{b}}$ & $22 \mathrm{~mL} / \mathrm{kg}$ per hour \\
\hline Mean daily urea on CRRT (high dose) & $11.7 \mathrm{mmol} / \mathrm{L}$ & $12.7 \mathrm{mmol} / \mathrm{L}$ \\
\hline Mean daily urea on CRRT (low dose) & $16.8 \mathrm{mmol} / \mathrm{L}$ & $15.9 \mathrm{mmol} / \mathrm{L}$ \\
\hline Daily fluid balance on therapy & $+130 \mathrm{~mL}$ & $-20 \mathrm{~mL}$ \\
\hline Survival at day 60 & $47.5 \%$ & Not reported \\
\hline Survival at day 90 & Not reported & $55.3 \%$ \\
\hline \multicolumn{3}{|l|}{ Percentage of survivors dependent on RRT } \\
\hline At day 28 & $45.2 \%$ & $13.3 \%$ \\
\hline At day 60 & $24.6 \%$ & Not reported \\
\hline At day 90 & Not reported & $5.6 \%$ \\
\hline
\end{tabular}

${ }^{a}$ Where baseline renal function was not available, patients are assumed to have normal baseline renal function. ${ }^{b}$ Dose was corrected for pre-dilution at median blood flow and replacement rates. APACHE, Acute Physiology and Chronic Health Evaluation; CKD, chronic kidney disease; CRRT, continuous renal replacement therapy; CVVHDF, continuous veno-venous hemodiafiltration; ICU, intensive care unit; IHD, intermittent hemodialysis; RENAL, Randomized Evaluation of Normal versus Augmented Level; RRT, renal replacement therapy; SLEDD, slow extended-duration daily dialysis; SOFA, Sequential Organ Failure Assessment; VA/NIH ATN, Veterans Affairs/National Institutes of Health Acute Renal Failure Trial Network.

their cardiovascular SOFA score was not more than 2. However, patients receiving only CRRT switched to IHD if their cardiovascular SOFA score was 0 or 1 for more than 24 hours. CRRT was provided to $69.7 \%$ of patients as their initial therapy [20]. Switching between modalities occurred at similar rates in high-intensity and lowintensity groups [20]. Among patients who survived to day $60,84.2 \%$ received IHD at some stage during their ICU stay [20]. Given the controversies in dose comparison between treatment modalities and the use of IHD in many patients, the ATN trial might best be described as a test of maximization of intensity of RRT within current US practice rather than a direct test of a dose-response relationship for CRRT. 
In comparison, 1,508 critically ill adults meeting predetermined criteria for the initiation of RRT in the RENAL study [8] were randomly assigned to post-dilution CVVHDF with an effluent flow of $40 \mathrm{~mL} / \mathrm{kg}$ per hour or $25 \mathrm{~mL} / \mathrm{kg}$ per hour. All patients received CRRT as their first mode of RRT; only a small proportion of patients (approximately 7\%) received IHD later in their ICU stay, and this proportion was similar to that of patients who remained dependent on dialysis at day 90. A small number of patients requiring an extended period of postICU RRT accounted for the higher mean duration of RRT $(11.5 \pm 18.0$ days and $13.0 \pm 20.8$ days in the two treatment groups) despite a duration of study treatment of only $5.9 \pm 7.7$ and $6.3 \pm 8.37$ days. The RENAL study thus constitutes a more direct measure of the relationship between intensity of CRRT and survival.

Both studies failed to detect any reduction in mortality associated with a more intensive RRT. In addition, no significant differences in mortality rates were observed between high-intensity and low-intensity treatment in pre-specified subgroups in either study. These subgroups included patients with sepsis and those requiring vasopressors. These results now provide definitive evidence that an increase of CRRT dose beyond conventional effluent flow rates of $25 \mathrm{~mL} / \mathrm{kg}$ per hour is not beneficial for unselected ICU patients with AKI. Importantly, both the ATN study and the RENAL study demonstrated that the prescribed dose is typically $10 \%$ to $15 \%$ less than the delivered dose in these patients, presumably because of treatment downtime. This observation is important because downtime may be longer outside of the environment of a clinical trial and clinicians seeking to replicate these outcomes will need to account for this in their prescription. In contrast to the within-trial comparisons, important differences between overall survival and recovery of renal function in the ATN and RENAL studies can be highlighted (Table 2). These differences do not detract from the consistent primary results within the trials and may be accounted for by differences in population and case mix. However, they also suggest that other aspects of RRT provision, such as timing of therapy [21] and prevalence of IHD, may impact outcomes and should be the subject of further study [3].

After the publication of the above pivotal trials, it was speculated that the relationship between CRRT dose and survival is at a plateau between 20 and $40 \mathrm{~mL} / \mathrm{kg}$ per hour but that lower or much higher doses could be associated with worse outcomes (Figure 1) [22]. Certainly, there is now little incentive to use doses of greater than $25 \mathrm{~mL} / \mathrm{kg}$ per hour in unselected ICU patients. It may be speculated that individual patients might benefit from differing doses of CRRT; however, there was no suggestion that specific groups benefited in subgroup analysis of the ATN and RENAL trials, indicating that identification of such patients may be difficult. Similarly, different target doses of CRRT may be sufficient at various stages of critical illness, but this question has not been examined in prospective randomized controlled trials.

The absence of improved survival with dose increment above $20 \mathrm{~mL} / \mathrm{kg}$ per hour should not be taken as an indication that assessment of dose is irrelevant, and lower intensities still will suffice. It can be reasonably presumed that some relationship for increasing survival with intensity of therapy exists as one increases intensity from no therapy to a greater level of therapy, with a plateau response occurring at or before 20 to $25 \mathrm{~mL} / \mathrm{kg}$ per hour. It seems unlikely that this plateau is occurring much before a dose of $20 \mathrm{~mL} / \mathrm{kg}$ per hour. In the DO-RE-MI study [12], patients in the second tertile of dose (23.6 to $30.9 \mathrm{~mL} / \mathrm{kg}$ per hour) had the lowest mortality, with an adjusted odds ratio for death of 0.67 , compared with doses of less than $23.6 \mathrm{~mL} / \mathrm{kg}$ per hour, but this trend was far from statistically significant $(P=0.196)$.

Historically, introduction of CRRT into the ICU led to improved survival when compared with previous use of thrice-weekly conventional IHD or acute peritoneal dialysis (PD) [23]. In this setting, use of CRRT led to improved azotemic control in comparison with the historical cohort, suggesting that increased survival may have been partly associated with delivery of a higher standardized dose of therapy. Similarly, a randomized control trial of CVVHF versus acute PD in patients with falciparum malaria or sepsis [24] demonstrated that CVVHF (mean prescribed dose of $19 \mathrm{~mL} / \mathrm{kg}$ per hour) was associated with improved survival over continuous PD (2L exchanges with 30-minute dwell time) (mortality of $15 \%$ versus $47 \% ; P=0.005)$. While modality-related factors undoubtedly played a role in these results, the rate of decline in creatinine was twice as fast in those treated with CVVHF in comparison with those treated with PD, suggesting that the dose of small-molecular clearance delivered may have, in part, determined outcome.

By analogy, in the setting of end-stage renal disease, while doses of thrice-weekly IHD above an equilibrated $\mathrm{Kt} / \mathrm{V}(\mathrm{eKt} / \mathrm{V})$ of greater than 1.16 have not been associated with improved outcomes [25], observational data have shown that an eKt/V of less than 1.05 is linearly associated with decreased survival in patients with endstage renal disease [26,27]. Thrice-weekly IHD with an eKt/V of 1.05 provides azotemic control similar to that of approximately $11 \mathrm{~mL} / \mathrm{kg}$ per hour of CRRT, according to the peak concentration method of dose comparison [28], and somewhat more if time-averaged urea concentration [29] is used as a comparator. It seems unlikely that the critically ill will have a lower requirement for RRT in comparison with stable HD patients. These considerations, therefore, suggest that we should not tolerate doses of CRRT in critically ill patients near the inflexion point 


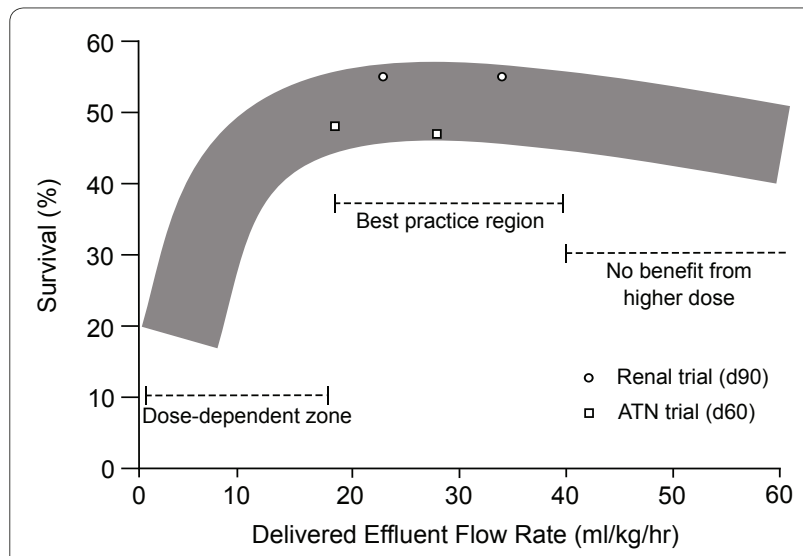

Figure 1. Possible relationship between delivered dose of continuous renal replacement therapy and survival, with results from the ATN and RENAL trials illustrated. ATN doses are corrected for pre-dilution. These studies indicate a plateau response at the dose ranges examined. To reproduce these results, clinicians will need to prescribe continuous renal replacement therapy doses above the lower target dose in the trial protocols (20 or $25 \mathrm{~mL} / \mathrm{kg}$ per minute) as larger periods of filter downtime can be expected outside a clinical trial environment. Below this best-practice region, survival is likely to be dose-dependent; however, the exact nature of this relationship has not been formally determined. Doses above the best-practice region are unlikely to be beneficial to unselected patients and could potentially be harmful. ATN, Veterans Affairs/National Institutes of Health Acute Renal Failure Trial Network; RENAL, Randomized Evaluation of Normal versus Augmented Level. Adapted from [18].

of the dose-response relationship seen in the chronic HD population. Collectively, all of the observations provide strong circumstantial evidence that CRRT doses of less than $20 \mathrm{~mL} / \mathrm{kg}$ per hour are likely to be harmful and should be avoided. Thus, to guarantee outcomes similar to those seen in the ATN and RENAL studies and to have confidence that an effective dose of CRRT has been delivered, clinicians should prescribe 20 to $30 \mathrm{~mL} / \mathrm{kg}$ per hour on the basis of body weight at time of commencement of CRRT and ensure that excessive periods off of treatment are not compromising dose delivered. Notably, international surveys $[11,12]$ have reported that, even now, a significant minority of patients receive treatment intensities of less than $20 \mathrm{~mL} / \mathrm{kg}$ per hour and may be suboptimally treated. If RRT doses are increased by adoption of these targets, clinicians should be aware that adjustments in drug (most importantly, antibiotic) dosing may be required to allow for increased clearances.

\section{Special circumstances}

A number of authors have hypothesized that subgroups of the critically ill, particularly those with sepsis or multiorgan failure, might benefit from a more intensive CRRT. It is thought that removal of circulating pro- and antiinflammatory mediators might blunt systemic derangement of immune responses in severe critical illness [30,31]. In the ATN and RENAL trials, there was no benefit from higher dose in any subgroup, including sepsis and vasopressor requirement. However, animal models [3234], which have suggested beneficial effects of CRRT on the severity of systemic inflammatory responses, employed very-high-dose therapy (greater than $50 \mathrm{~mL} / \mathrm{kg}$ per hour) initiated very early in the course of illness (prior to overt renal dysfunction). Dose-response studies of conventional CRRT, such as the ATN and RENAL trials, were not intended to examine these pleiotropic effects of CRRT in critical illness. A detailed discussion of this topic is beyond the scope of this review; however, as such immunemodulating effects are often cited as a rationale for dose adjustment of CRRT in severe sepsis, it is pertinent to briefly discuss the current evidence base for such use of high-intensity CRRT in carefully selected patients.

Very-high-volume CRRT has been examined in uncontrolled clinical trials and case series with suggestion of benefit [35-39]. As removal of middle-molecularweight mediators was desired, purely convective therapy (HF) was used in most of these studies. Very-highvolume HF has been defined as a dose of greater than $50 \mathrm{~mL} / \mathrm{kg}$ per hour [40], although many studies have used higher doses. In practice, delivery of doses of CVVHF in excess of $50 \mathrm{~mL} / \mathrm{kg}$ per hour is complex, presenting a number of clinical and technical challenges [40] that may account for the lack of high-quality clinical trial data to confirm or refute a benefit. An MC-RCT, the IVOIRE (High Volume in Intensive Care) study, examining the use of high-volume versus intermediate-dose CRRT (70 versus $35 \mathrm{~mL} / \mathrm{kg}$ per hour for 96 hours in patients with septic shock and moderate kidney injury) has recently stopped recruiting as interim analysis revealed lowerthan-expected mortality in all patients, rendering the planned study size (480 patients) insufficiently powerful to prove an effect on survival [41]. Interest has thus focused on other methods of blood purification including coupled plasma filtration with bioadsorption [42] or hemofiltation using high-cutoff point (greater than $50 \mathrm{kDa}$ ) membranes [43,44] - that may be easier to clinically implement. As yet, the adjunctive uses of CRRT and related technologies for the treatment of severe sepsis and multi-organ failure remain experimental and are subject to ongoing trials. However, given the complexity of these treatments and the diverse patient population, direct proof of survival benefit may be difficult to obtain and surrogate endpoints such as vasopressor requirements and organ failure scoring may form the basis of practice recommendations in the future.

\section{Conclusions}

The ATN and RENAL studies have now established an upper limit of intensity for CRRT. In addition, they found 
This article is part of the review series on Renal replacement therapy, edited by John Kellum and Lui Forni.

Other articles in the series can be found online at

http://ccforum.com/articles/theme-series.asp?series=CC_Renal

no evidence to suggest that any specific subgroups would benefit from higher doses of RRT, refuting previous smaller studies [14]. The findings of these studies, however, do not imply that the estimation of dose is unimportant. A dose-response relationship is likely at lower treatment intensities (that is, less than $20 \mathrm{~mL} / \mathrm{kg}$ per hour), and a significant minority of patients still receive treatment intensities less than this [11,12]. Given the likelihood of a dose-response relationship somewhere below $20 \mathrm{~mL} / \mathrm{kg}$ per hour, delivery of doses lower than this should be avoided [22]. To ensure outcomes similar to those seen in the ATN and RENAL trials, clinicians should also prescribe CRRT on the basis of patient body weight to the established effluent flow rate target of 20 to $25 \mathrm{~mL} / \mathrm{kg}$ of body weight per hour.

\section{Abbreviations}

AKI, acute kidney injury; ATN, Veterans Affairs/National Institutes of Health Acute Renal Failure Trial Network; CRRT, continuous renal replacement therapy; CVVHDF, continuous veno-venous hemodiafiltration; CVVHF, continuous veno-venous hemofiltration; DO-RE-MI, Dose Response Multicentre International collaborative initiative; eKt/N, equilibrated Kt/N; GFR, glomerular filtration rate; $\mathrm{HD}$, hemodialysis; $\mathrm{HF}$, hemofiltration; ICU, intensive care unit; $\mid H D$, intermittent hemodialysis; $M C-R C T$, multi-center randomized controlled trial; PD, peritoneal dialysis; RENAL, Randomized Evaluation of Normal versus Augmented Level; RRT, renal replacement therapy; SOFA, Sequential Organ Failure Assessment.

\section{Competing interests}

RB was lead author of the Randomized Evaluation of Normal versus Augmented Level (RENAL) Replacement Therapy Study and has received consulting fees from Gambro (Stockholm, Sweden), Biosite (San Diego, CA, USA), Abbott Diagnostics (Abbott Park, IL, USA), and Philips Medical Systems (Andover, MA, USA) and grant support from Fresenius Kabi (Bad Homburg, Germany), Bard (Covington, GA, USA), Pfizer Inc (New York, NY, USA), and Gambro. JRP and AS declare that they have no competing interests.

Published: 18 March 2011

\section{References}

1. Chertow GM, Burdick E, Honour M, Bonventre JV, Bates DW: Acute kidney injury, mortality, length of stay, and costs in hospitalized patients. J Am SoC Nephrol 2005, 16:3365-3370.

2. Uchino S, Kellum JA, Bellomo R, Doig GS, Morimatsu H, Morgera S, Schetz M, Tan I, Bouman C, Macedo E, Gibney N, Tolwani A, Ronco C, Beginning and Ending Supportive Therapy for the Kidney (BEST Kidney) Investigators: Acute renal failure in critically ill patients: a multinational, multicenter study. JAMA 2005, 294:813-818

3. Prowle JR, Bellomo R: Continuous renal replacement therapy: recent advances and future research. Nat Rev Nephrol 2010, 6:521-529.

4. The VA/NIH Acute Renal Failure Trial Network: Intensity of renal support in critically ill patients with acute kidney injury. N Engl J Med 2008, 359:7-20.

5. Bagshaw SM, Bellomo R, Devarajan P, Johnson C, Karvellas CJ, Kutsiogiannis DJ, Mehta R, Pannu N, Romanovsky A, Sheinfeld G, Taylor S, Zappitelli M, Gibney RT: Review article: renal support in critical illness. Can J Anaesth 2010, 57:999-1013.

6. Ronco C, Ricci Z: Renal replacement therapies: physiological review. Intensive Care Med 2008, 34:2139-2146.
7. Cole L, Bellomo R, Silvester W, Reeves JH: A prospective, multicenter study of the epidemiology, management, and outcome of severe acute renal failure in a "closed" ICU system. Am J Respir Crit Care Med 2000, 162:191-196.

8. RENAL Replacement Therapy Study Investigators, Bellomo R, Cass A, Cole L, Finfer S, Gallagher M, Lo S, McArthur C, McGuinness S, Myburgh J, Norton R, Scheinkestel C, Su S: Intensity of continuous renal-replacement therapy in critically ill patients. N Engl J Med 2009, 361:1627-1638.

9. Ricci Z, Salvatori G, Bonello M, Pisitkun T, Bolgan I, D'Amico G, Dan M, Piccinni $\mathrm{P}$, Ronco C: In vivo validation of the adequacy calculator for continuous renal replacement therapies. Crit Care 2005, 9:R266-R273.

10. Fealy N, Baldwin I, Bellomo R: The effect of circuit "down-time" on uraemic control during continuous veno-venous haemofiltration. Crit Care ResusC 2002, 4:266-270.

11. Uchino S, Bellomo R, Morimatsu H, Morgera S, Schetz M, Tan I, Bouman C, Macedo E, Gibney N, Tolwani A, Oudemans-van Straaten H, Ronco C, Kellum $J A$ : Continuous renal replacement therapy: a worldwide practice survey: The Beginning and Ending Supportive Therapy for the Kidney (B.E.S.T. Kidney) Investigators. Intensive Care Med 2007, 33:1563-1570.

12. Vesconi S, Cruz DN, Fumagalli R, Kindgen-Milles D, Monti G, Marinho A, Mariano F, Formica M, Marchesi M, René R, Livigni S, Ronco C, DOse REsponse Multicentre International collaborative Initiative (DO-RE-MI Study Group): Delivered dose of renal replacement therapy and mortality in critically ill patients with acute kidney injury. Crit Care 2009, 13:R57.

13. Lameire N, Van Biesen W, Vanholder R: Dose of dialysis in the intensive care unit: is the venom in the dose or in the clinical experience? Crit Care 2009, 13:155.

14. Ronco C, Bellomo R, Homel P, Brendolan A, Dan M, Piccinni P, La Greca G: Effects of different doses in continuous veno-venous haemofiltration on outcomes of acute renal failure: a prospective randomised trial. Lancet 2000, 356:26-30.

15. Saudan P, Niederberger M, De Seigneux S, Romand J, Pugin J, Perneger T, Martin PY: Adding a dialysis dose to continuous hemofiltration increases survival in patients with acute renal failure. Kidney Int 2006, 70:1312-1317.

16. Ricci Z, Ronco C, Bachetoni A, D'amico G, Rossi S, Alessandri E, Rocco M, Pietropaoli P: Solute removal during continuous renal replacement therapy in critically ill patients: convection versus diffusion. Crit Care 2006, 10:R67.

17. Tolwani AJ, Campbell RC, Stofan BS, Lai KR, Oster RA, Wille KM: Standard versus high-dose CVVHDF for ICU-related acute renal failure. J Am SOC Nephrol 2008, 19:1233-1238.

18. Bouman CS, Oudemans-Van Straaten HM, Tijssen JG, Zandstra DF, Kesecioglu $\mathrm{J}$ : Effects of early high-volume continuous venovenous hemofiltration on survival and recovery of renal function in intensive care patients with acute renal failure: a prospective, randomized trial. Crit Care Med 2002, 30:2205-2211

19. Bellomo R, Warrillow SJ, Reade MC: Why we should be wary of single-center trials. Crit Care Med 2009, 37:3114-3119.

20. Palevsky PM, O'Connor TZ, Chertow GM, Crowley ST, Zhang JH, Kellum JA, US Department of Veterans Affairs/National Institutes of Health Acute Renal Failure Trial Network: Intensity of renal replacement therapy in acute kidney injury: perspective from within the Acute Renal Failure Trial Network Study. Crit Care 2009, 13:310.

21. Bouman CS, Oudemans-van Straaten HM: Timing of renal replacement therapy in critically ill patients with acute kidney injury. Curr Opin Crit Care 2007, 13:656-661.

22. Kellum JA, Ronco C: Dialysis: results of RENAL--what is the optimal CRRT target dose? Nat Rev Nephrol 2010, 6:191-192.

23. Bellomo R, Mansfield D, Rumble S, Shapiro J, Parkin G, Boyce N: Acute renal failure in critical illness. Conventional dialysis versus acute continuous hemodiafiltration. ASAIO J 1992, 38:M654-M657.

24. Phu NH, Hien TT, Mai NT, Chau TT, Chuong LV, Loc PP, Winearls C, Farrar J, White N, Day N: Hemofiltration and peritoneal dialysis in infectionassociated acute renal failure in Vietnam. N Engl J Med 2002, 347:895-902.

25. Eknoyan G, Beck GJ, Cheung AK, Daugirdas JT, Greene T, Kusek JW, Allon M, Bailey J, Delmez JA, Depner TA, Dwyer JT, Levey AS, Levin NW, Milford E, Ornt DB, Rocco MV, Schulman G, Schwab SJ, Teehan BP, Toto R, Hemodialysis (HEMO) Study Group: Effect of dialysis dose and membrane flux in maintenance hemodialysis. N Engl J Med 2002, 347:2010-2019.

26. Owen WF, Lew NL, Liu Y, Lowrie EG, Lazarus JM: The urea reduction ratio and serum albumin concentration as predictors of mortality in patients undergoing hemodialysis. N Engl J Med 1993, 329:1001-1006. 
27. Gotch FA, Gentile DE, Keen ML, Amerling R, Folkert VW, Kliger AS, Shapiro WB: The incident patient cohort study design with uncontrolled dose. Substantial over-estimation of mortality as a function of peritoneal dialysis dose? ASAIO J 1996, 42:M514-M517.

28. Gotch FA: The current place of urea kinetic modelling with respect to different dialysis modalities. Nephrol Dial Transplant 1998, 13 Suppl 6:10-14.

29. Casino FG, Lopez T: The equivalent renal urea clearance: a new parameter to assess dialysis dose. Nephrol Dial Transplant 1996, 11:1574-1581.

30. Tetta C, Bellomo R, D'Intini V, De Nitti C, Inguaggiato P, Brendolan A, Ronco C: Do circulating cytokines really matter in sepsis? Kidney Int Supp/ 2003, (84):S69-S71.

31. Joannes-Boyau O, Honore PM, Boer W: Hemofiltration: The case for removal of sepsis mediators from where they do harm. Crit Care Med 2006, 34:2244-2246

32. Grootendorst $A F$, van Bommel EF, van der Hoven $B$, van Leengoed $L A$, van Osta AL: High volume hemofiltration improves right ventricular function in endotoxin-induced shock in the pig. Intensive Care Med 1992, 18:235-240.

33. Bellomo R, Kellum JA, Gandhi CR, Pinsky MR, Ondulik B: The effect of intensive plasma water exchange by hemofiltration on hemodynamics and soluble mediators in canine endotoxemia. Am J Respir Crit Care Med 2000, 161:1429-1436.

34. Yekebas EF, Eisenberger CF, Ohnesorge $H$, Saalmüller A, Elsner HA, Engelhardt M, Gillesen A, Meins J, The M, Strate T, Busch C, Knoefel WT, Bloechle C, Izbicki $J R$ : Attenuation of sepsis-related immunoparalysis by continuous venovenous hemofiltration in experimental porcine pancreatitis. Crit Care Med 2001, 29:1423-1430

35. Honore PM, Jamez J, Wauthier M, Lee PA, Dugernier T, Pirenne B, Hanique G, Matson JR: Prospective evaluation of short-term, high-volume isovolemic hemofiltration on the hemodynamic course and outcome in patients with intractable circulatory failure resulting from septic shock. Crit Care Med 2000, 28:3581-3587.

36. Joannes-Boyau O, Rapaport S, Bazin R, Fleureau C, Janvier G: Impact of high volume hemofiltration on hemodynamic disturbance and outcome during septic shock. ASAIO J 2004, 50:102-109.
37. Laurent I, Adrie C, Vinsonneau C, Cariou A, Chiche JD, Ohanessian A, Spaulding C, Carli P, Dhainaut JF, Monchi M: High-volume hemofiltration after out-of-hospital cardiac arrest: a randomized study. J Am Coll Cardiol 2005, 46:432-437.

38. Ratanarat R, Brendolan A, Piccinni P, Dan M, Salvatori G, Ricci Z, Ronco C. Pulse high-volume haemofiltration for treatment of severe sepsis: effects on hemodynamics and survival. Crit Care 2005, 9:R294-R302.

39. Cornejo R, Downey P, Castro R, Romero C, Regueira T, Vega J, Castillo L, Andresen M, Dougnac A, Bugedo G, Hernandez G: High-volume hemofiltration as salvage therapy in severe hyperdynamic septic shock. Intensive Care Med 2006, 32:713-722.

40. Bouman CS, Oudemans-van Straaten HM, Schultz MJ, Vroom MB: Hemofiltration in sepsis and systemic inflammatory response syndrome: the role of dosing and timing. J Crit Care 2007, 22:1-12.

41. Bellomo R, Palevsky PM, Bagshaw SM, Gibney N, McAlister FA, Honore PM, Joannes-Boyau O, Prowle J, Haase M, Cruz DN, Ronco C: Recent Trials in Critical Care Nephrology. Contrib Nephrol 2010, 165:299-309.

42. Ronco C, Bellomo R, Kellum JA: Continuous renal replacement therapy: opinions and evidence. Adv Ren Replace Ther 2002, 9:229-244.

43. Haase M, Bellomo R, Baldwin I, Haase-Fielitz A, Fealy N, Davenport P, Morgera S, Goehl H, Storr M, Boyce N, Neumayer HH: Hemodialysis membrane with a high-molecular-weight cutoff and cytokine levels in sepsis complicated by acute renal failure: a phase 1 randomized trial. Am J Kidney Dis 2007 50:296-304.

44. Morgera S, Haase M, Kuss T, Vargas-Hein O, Zuckermann-Becker H, Melzer C, Krieg H, Wegner B, Bellomo R, Neumayer HH: Pilot study on the effects of high cutoff hemofiltration on the need for norepinephrine in septic patients with acute renal failure. Crit Care Med 2006, 34:2099-2104.

doi:10.1186/cc9415

Cite this article as: Prowle JR, et al: Optimal dose of continuous renal replacement therapy in acute kidney injury. Critical Care 2011, 15:207. 